\begin{tabular}{|c|l|}
\hline Title & Influence of winter road conditions and signal delay on pedestrian route choice in Japan's snowiest metropolis \\
\hline Author(s) & Mural eetharan, Thambiah; Meguro, Kunio; A dachi, Takeo; Hagiwara, Toru; Kagaya, Sei 'ichi \\
\hline Citation & Transportation reserach record: Journal of the Transportation Research Board, 1939, 145-153 \\
\hline Issue Date & 2005 \\
\hline Doc URL & http:/hdl.handle.net/2115/14411 \\
\hline Type & article (author version) \\
\hline File Information & TRB_2005.pdf \\
\hline
\end{tabular}

Instructions for use 


\title{
Influence of Winter Road Conditions and Signal Delay on Pedestrian Route Choice in Japan's Snowiest Metropolis
}

\author{
Thambiah Muraleetharan, Kunio Meguro, Takeo Adachi, \\ Toru Hagiwara, and Sei'ichi Kagaya
}

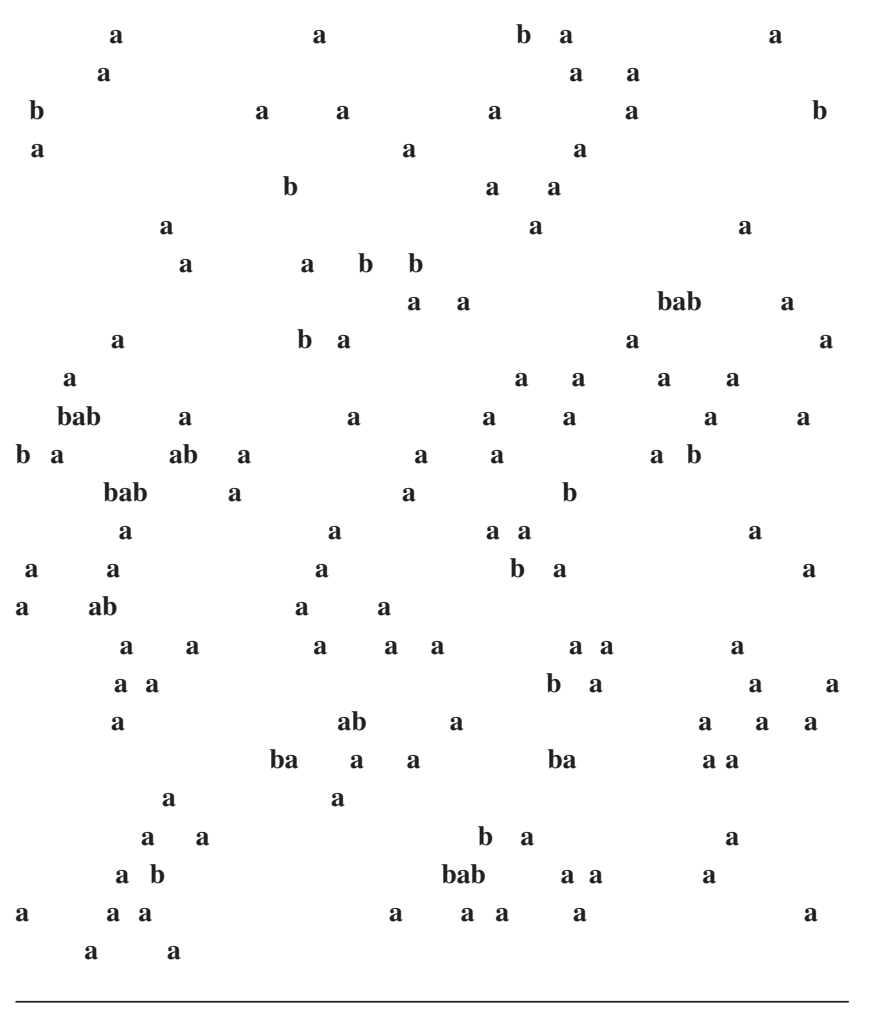

In Sapporo, Japan, winter lasts almost half the year. The annual average snowfall is $5 \mathrm{~m}$, and the mean snow depth is $1 \mathrm{~m}$. Although many metropolises in the world are much colder than Sapporo, no other big city has snowfall as heavy Sapporo, which is home to more than 1.8 million people. Snow pervades the urban environment there in the winter. As a result, the street environment changes with the seasons. In winter, cycling becomes impossible because of the snow on the streets. Therefore, the number of pedestrians on the sidewalks increases. Pedestrian traffic flow increases in winter, and a major concern of

T. Muraleetharan, K. Meguro, T. Hagiwara, and S. Kagaya, Transportation and Traffic Engineering Laboratory, Graduate School of Engineering, Hokkaido University, Kita-13, Nishi-8, Kita-ku, Sapporo 060-8628, Japan. T. Adachi, Department of Civil Engineering, Hokkaido College, Senshu University, Bibai 1610-1, Bibai, 079-0193, Japan.

Transportation Research Record: Journal of the Transportation Research Board, No. 1939, Transportation Research Board of the National Academies, Washington, D.C., 2005, pp. 145-153. pedestrians is the road surface condition. Pedestrians face difficulties in walking because of slippery walkways. Falling accidents on slippery walkways cause serious injuries (1). Improvement of slippery walkway conditions is a major task for winter road maintenance in Sapporo. However, the effect of the improvement of road surface conditions on pedestrian behavior is not well-known, and it must be clarified for the purpose of understanding the socioeconomic benefits of such improvements. The route choice behavior of pedestrians must be investigated in detail for winter road maintenance to be effective in Sapporo.

Several studies on pedestrian planning focused on the basic concepts of pedestrian facilities. The 2000 edition of the Highway Capacity Manual provides general guidelines for capacity and level-of-service analyses for pedestrian paths based on several factors (2). Different factors affect the walking behavior of pedestrians, such as the distance to their destination, the personal characteristics of pedestrians, trip purpose, route familiarity, recreational points of interest, and environmental conditions. One study addressed bottlenecks and the presence of obstructions on walkways (3). Models were developed on the basis of a quantification theory by considering sidewalk type, the presence of pedestrian facilities, the number of attractions, and surface quality as explanatory variables (4-6). A review of previous research papers in this area indicated that the following features influence the route choice behavior of pedestrians.

- Distance between origin and destination,

- Walkway width,

- Surface characteristics (paved versus unpaved),

- Recreational points of interest,

- Available facilities, and

- Conflicts with motor traffic.

Although extensive research on pedestrians' walking behavior has been conducted, few studies have dealt with walking behavior on icy surfaces. How pedestrians choose their routes in winter is not clear, and many aspects of that choice are still not understood properly.

This paper investigates the route choice behavior of pedestrians in winter and the effectiveness of the winter road improvements in improving pedestrian mobility in Sapporo. In general, if there are several alternative routes to a particular destination, people choose the shortest route. However, the street network in Sapporo is designed on a grid, and route selection has little effect on the distance between a given origin and destination. Therefore, it has been thought that pedestrians select their routes according to the road surface conditions 
and the delay at signalized intersections. On the basis of this judgment, it was hypothesized that during the snowy season, not only the traffic signal but also the road surface condition affect the route choice behavior of pedestrians. Field surveys and questionnaire surveys were conducted to test this hypothesis.

\section{FIELD SURVEY}

To fulfill the desired objective, a field survey was conducted by collecting relevant information about pedestrian behavior in winter. Field measurements help with the collection of the behavior of pedestrians on site. Video recordings were made to capture the movements of pedestrians.

\section{Experimental Site}

The selected site should satisfy three conditions:

1. During the snowy season each route needs to have a different surface condition.

2. The study area should be on level terrain to avoid the influence of the walkway grade on route choice behavior.

3. The destination point must be diagonal from the origin point.

The selected field survey site met these conditions. As shown in Figure 1, the routes from the nearest subway station to the entrance of Hokkaido University were designated for the investigation. Video cameras were positioned as shown in Figure 1. The cameras were fixed at the locations indicated by Points A, B, C, and D, with Point B indicating the origin and Point $\mathrm{D}$ indicating the destination, and recorded the following:

- The camera at Point A records the pedestrians exiting the subway station.

- The camera at Point B records the pedestrians arriving at the origin.

- The camera at Point $\mathrm{C}$ records the pedestrians walking along Routes 1 and 2.

- The camera at Point D records the pedestrians as they reach the destination.

\section{Experimental Setup}

Figure 2 shows the configuration of the crosswalk used for the investigation. The video cameras were placed at a corner of each intersection from which the researchers could see all the crosswalks. This allowed the pedestrian signal to be in clear view so that the camera could capture both the signal change and the movements of pedestrians. How pedestrians choose their routes was investigated by observing their movements on Routes 1 and 2. The effective green time for pedestrians and the total time for a signal to complete one cycle were also recorded by the cameras. At each change of pedestrian signal (red to green), a signal was recorded by flashing a light at the camera to differentiate each cycle from the next.

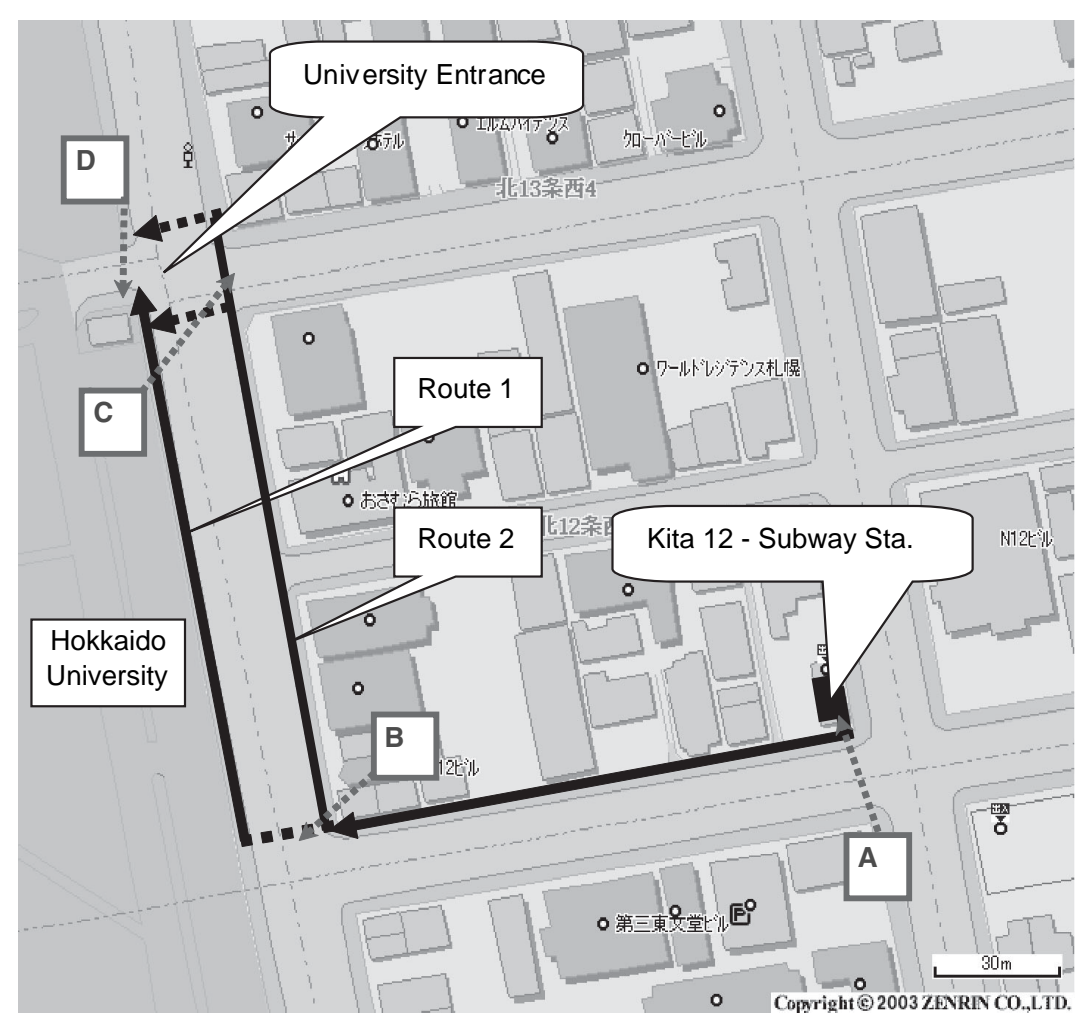

FIGURE 1 Experimental site. 


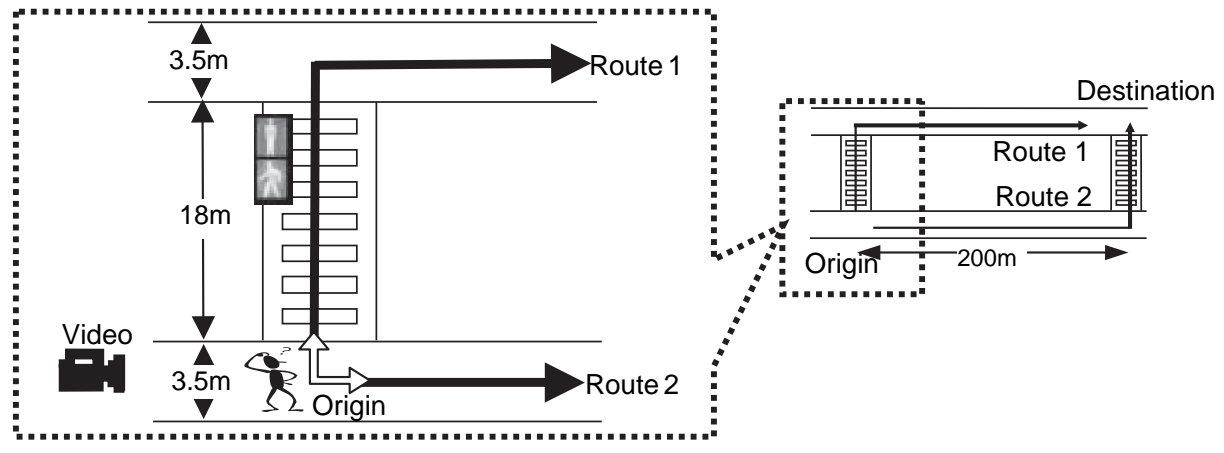

FIGURE 2 Configuration of crosswalk used for investigation.

\section{Recording Conditions}

The morning peak period (8:30 to 9:00 a.m.) was chosen for investigation, because many pedestrians commute to work and school during this time. On November 11, 2003, 175 pedestrians were observed by video recording. All the streets were bare, as there had been no snowfall until that day. To verify the changes in pedestrian route choice behavior because of the presence of snow, video recordings were again made on January 20, 2004, at the same locations. On that day, the streets were filled with snow. The movements of 317 pedestrians were recorded with video cameras. Figure 3 shows a surveyed location with two different surface conditions. Snow accumulated on Route 1 because there was no road heating on that route. Part of Route 2 had road heating, and the rest of that route was well maintained by sidewalk snow removal for pedestrian mobility.

\section{Tracking Pedestrians On-Screen}

The signal change and the movements of each pedestrian were captured by playing the video records on a television screen. The investigation focused on pedestrians whose destinations were diagonal from their origins. On the television screen, pedestrians were ran- domly tracked from the exit of subway station to the entrance of the Hokkaido University, which is diagonal from the subway station. The observation stopped when the target went toward a different destination.

\section{Numerical Data from Video Survey}

A pedestrian selecting Route 1 or Route 2 was recorded by using a dummy variable. The value is 1 if he or she selects Route 1 ; otherwise, it is 0 . A sample of the numerical data derived from the video records is shown in Table 1. The ages and genders of the subjects were judged by the observers. The personal characteristics of the pedestrians observed are tabulated in Table 2.

\section{RESULTS OF FIELD SURVEY}

Table 3 shows the selection ratio for Route 1 under two different conditions. According to these results, when the signal is green the probability that Route 1 will be selected is extremely high. This finding indicates that pedestrians are highly influenced by the status of the signal and the tendency for Route 1 to be selected becomes extremely

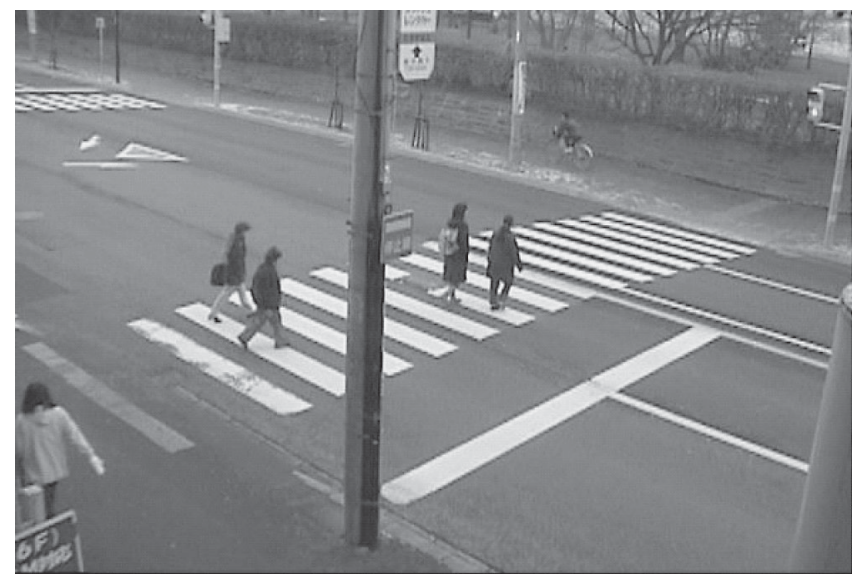

(a)

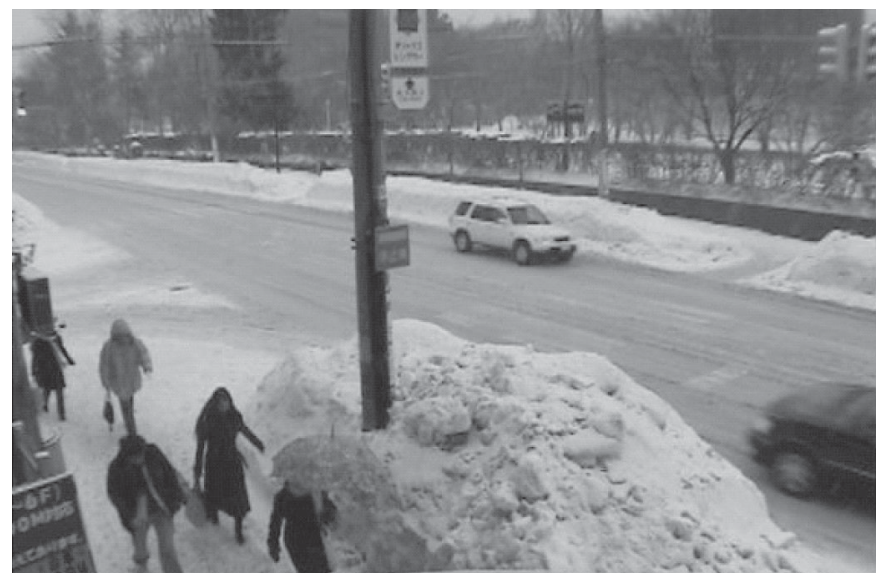

(b)

FIGURE 3 Surveyed location under two different surface conditions: (a) November 11, 2005, and (b) January $20,2004$. 
TABLE 1 Sample of Numerical Data from Video Survey

\begin{tabular}{lcccc}
\hline Number & $\begin{array}{l}\text { Route } 1=1 \\
\text { Route } 2=0\end{array}$ & $\begin{array}{l}\text { Delay } \\
(\mathrm{s})\end{array}$ & $\begin{array}{l}\text { Gender } \\
\text { Male=1 } \\
\text { Female=0 }\end{array}$ & $\begin{array}{l}\text { Age range } \\
\text { (years) }\end{array}$ \\
\hline 1 & 1 & 0 & 1 & $40-49$ \\
2 & 1 & 0 & 0 & $20-29$ \\
3 & 1 & 0 & 0 & $20-29$ \\
$\ldots$ & $\ldots$ & $\ldots$ & $\ldots$ & $\ldots$ \\
$\ldots$ & $\ldots$ & $\ldots$ & $\ldots$ & $\ldots$ \\
315 & 0 & 38 & 1 & $40-49$ \\
316 & 0 & 36 & 1 & $20-29$ \\
317 & 0 & 35 & 0 & $40-49$ \\
\hline
\end{tabular}

high, regardless of the surface conditions. However, when the signal is red and the walkway surface is slippery, the probability that Route 1 will be selected decreases by $9 \%$. Figure 4 shows the probability that Route 1 will be selected with the delay from 0 to $45 \mathrm{~s}$. Figure 4 shows that the probability that Route 1 will be selected is almost $100 \%$ when the delay is $0 \mathrm{~s}$ but becomes very low when the delay exceeds $15 \mathrm{~s}$.

\section{MODELING OF OBSERVED BEHAVIOR OF PEDESTRIANS}

The following logit model was developed to quantitatively express the route choice behavior of pedestrians:

$P=\frac{\exp (\alpha+\beta T)}{[1+\exp (\alpha+\beta T)]}$

where

$$
\begin{aligned}
\alpha \text { and } \beta & =\text { parameters, } \\
P & =\text { probability that a route will be selected, and } \\
T & =\text { pedestrian signal delay }(\mathrm{s}) .
\end{aligned}
$$

The route choice model was estimated by using a software application called LIMDEP 7.0, which performs a standard numerical logit procedure (7). The values of the parameters obtained are shown in Table 4 . For a two-sided $t$-test, the approximate $5 \%$ critical value is 1.96. $t$-values are used to test the null hypothesis that there is a zero correlation between independent variables and the probability of route choice. Because the calculated $t$-values exceed the critical value of
TABLE 2 Personal Characteristics of Observed Pedestrians

\begin{tabular}{llcc}
\hline \multirow{2}{*}{ Characteristic } & Categories & $\begin{array}{l}\text { Number of } \\
\text { Targets }\end{array}$ & Percentage \\
\hline Gender & Male & 199 & 40 \\
& Female & 293 & 60 \\
Age range (estimated & <20 years & 3 & 1 \\
by observer) & 20-29 years & 274 & 56 \\
& 30-39 years & 78 & 16 \\
& 40-49 years & 73 & 15 \\
& 50-59 years & 52 & 2 \\
& $>59$ years & 12 & 2 \\
\hline
\end{tabular}

1.96, the null hypothesis is rejected in favor of the alternative hypothesis. Therefore, the independent variables selected and the probability of route choice are correlated. The predicted outcome values for both the presnow and the postsnow models were quite high (90\% and $91 \%$, respectively).

The calculated parameters were used to model the probability that a route would be selected as a function of road surface condition and signal delay. Figure 5 illustrates that whenever the wait becomes long, the probability that Route 1 will be selected decreases for both environmental conditions. In addition, the probability that Route 1 will be selected became low when the road surface was slippery. This shows that during the snowy season, people select Route 2 because part of this route is kept bare by road heating.

\section{QUESTIONNAIRE SURVEY}

The behaviors of pedestrians can be examined by video camera recording. However, information such as pedestrian route preferences and the personal characteristics of pedestrians cannot be accurately obtained from video recordings. In addition, it is hard to find an investigation site with alternative routes with different surface conditions. Questionnaire surveys can describe different routes with various road surface conditions. The personal characteristics of pedestrians can also be obtained more accurately from the information collected by questionnaire surveys.

\section{Questionnaire Design and Distribution}

Three levels of road surface slipperiness were defined, as shown in Table 5. If there is a choice of two routes, then there are three lev-

TABLE 3 Probability That Route 1 Will Be Selected Under Different Street Conditions

\begin{tabular}{lll}
\hline & \multicolumn{2}{l}{ Probability of Route 1 Being Selected } \\
\cline { 2 - 3 } Street Environment & Green Signal & Red Signal \\
\hline $\begin{array}{l}\text { Presnow bare surface } \\
\text { (November 11, 2003) }\end{array}$ & $99 \%(=72$ ped/73ped $)$ & $21 \%(=21$ ped $/ 102$ ped $)$ \\
$\begin{array}{l}\text { Postsnow icy slippery surface } \\
\text { (January 20, 2004) }\end{array}$ & $98 \%(=151$ ped/154ped $)$ & $12 \%(=20$ ped $/ 163 p e d)$ \\
\hline
\end{tabular}

ped $=$ pedestrian 


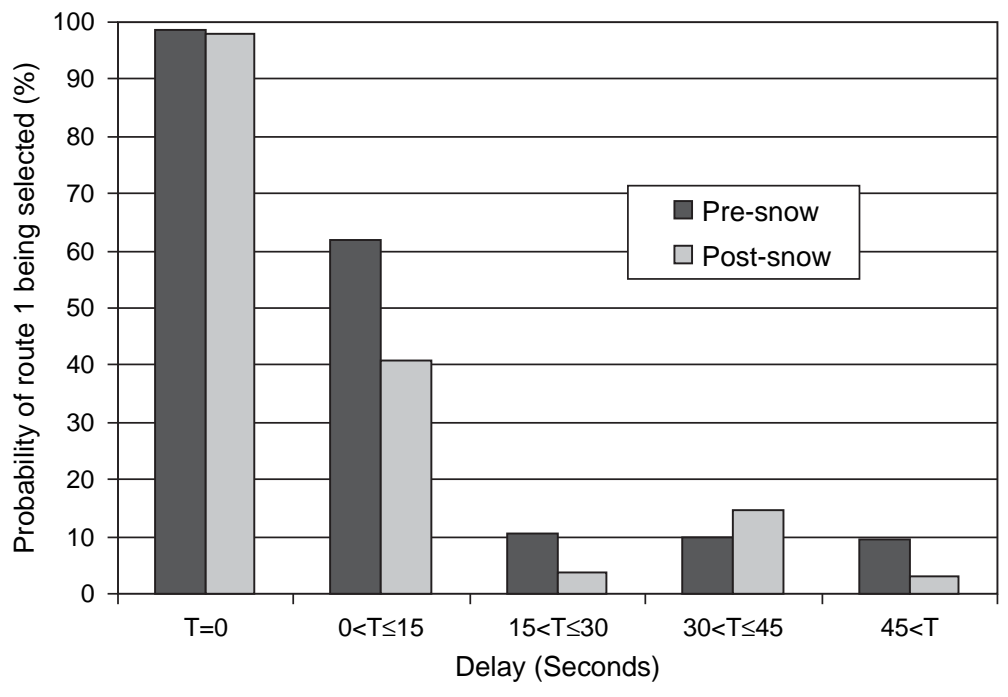

FIGURE 4 Probability that Route 1 will be selected versus pedestrian signal delay $(T)$.

els for Route 1 multiplied by three levels for Route 2, which gives nine combinations for questionnaire design. Combinations for which the road surface conditions were the same for both Routes 1 and 2 were removed from the questionnaire. This left the six combinations ( $A_{1}$ to $A_{6}$ ) indicated in Figure 6. The questionnaires were designed by using these six combinations of road surface conditions. Figure 7 shows a sample questionnaire used for the survey. The questionnaire survey was administered at the same location where the video investigation was conducted. To allow close comparison with the video investigation, the questionnaires were distributed to the same target groups: commuters going to work and school from 8:30 to 9:00 a.m. on November 16, 2003, and January 18, 2004. The distribution of the questionnaires on the same days as the video observations could have disrupted the usual behavior of pedestrians. Therefore, the questionnaires were distributed on different days. However, the days for the distribution of the questionnaires were chosen to have environmental conditions similar to those on the days of the video observations. In the questionnaire, the respondents were requested to choose either Route 1 or Route 2, which were illustrated with different surface conditions. Of the 320 questionnaires distributed, 142 were returned, giving a response rate of $44 \%$. The valid sample size was 137 , since the responses of five respondents were later deemed invalid. The personal characteristics of the respondents are shown in Table 6.

\section{Modeling of Pedestrians' Behaviors with Data from Questionnaire Survey}

The probability that a pedestrian would choose a route is given by the following logit model:

$$
P=\frac{\exp \left(\alpha+\beta T+\sum_{i=1}^{6} \gamma_{i} A_{i}\right)}{\left[1+\exp \left(\alpha+\beta T+\sum_{i=1}^{6} \gamma_{i} A_{i}\right)\right]}
$$

where

$$
\begin{aligned}
\alpha, \beta, \text { and } \gamma= & \text { parameters, } \\
P= & \text { probability that a route will be selected, } \\
T= & \text { pedestrian signal delay (s), and } \\
A_{i}= & \text { dummy variable (with } i \text { equal to } 1 \text { to } 6 \text { ) to show the } \\
& \text { combination of road surface conditions shown in } \\
& \text { Figure } 6 b . A_{i} \text { is equal to } 1 \text { if the case is the same as } \\
& \text { any of the conditions shown in Figure } 6 b ; \text { otherwise, } \\
& A_{i} \text { is } 0 .
\end{aligned}
$$

The data obtained from the questionnaire survey were imported into the LIMDEP statistical software for modeling analysis. The calculated

TABLE 4 Parameter Values for Pedestrian Route Choice Model Obtained from Field Observations

\begin{tabular}{llcccc}
\hline $\begin{array}{l}\text { Street } \\
\text { Environment }\end{array}$ & Parameter & $t$-Value & $p$-Value & $\begin{array}{l}\text { Predicted } \\
\text { Outcome }\end{array}$ & $\begin{array}{l}\text { Likelihood } \\
\text { Ratio }\end{array}$ \\
\hline Presnow & $\alpha=2.187$ & 6.68 & 0.00 & $90 \%$ & 0.53 \\
$\quad$ November 11, 2003) & $\beta=-0.118$ & -7.42 & 0.00 & & \\
$\quad \begin{array}{l}\text { Postsnow } \\
\quad \text { January 20, 2004) }\end{array}$ & $\alpha=2.263$ & 9.125 & 0.00 & $91 \%$ & 0.60 \\
\hline
\end{tabular}




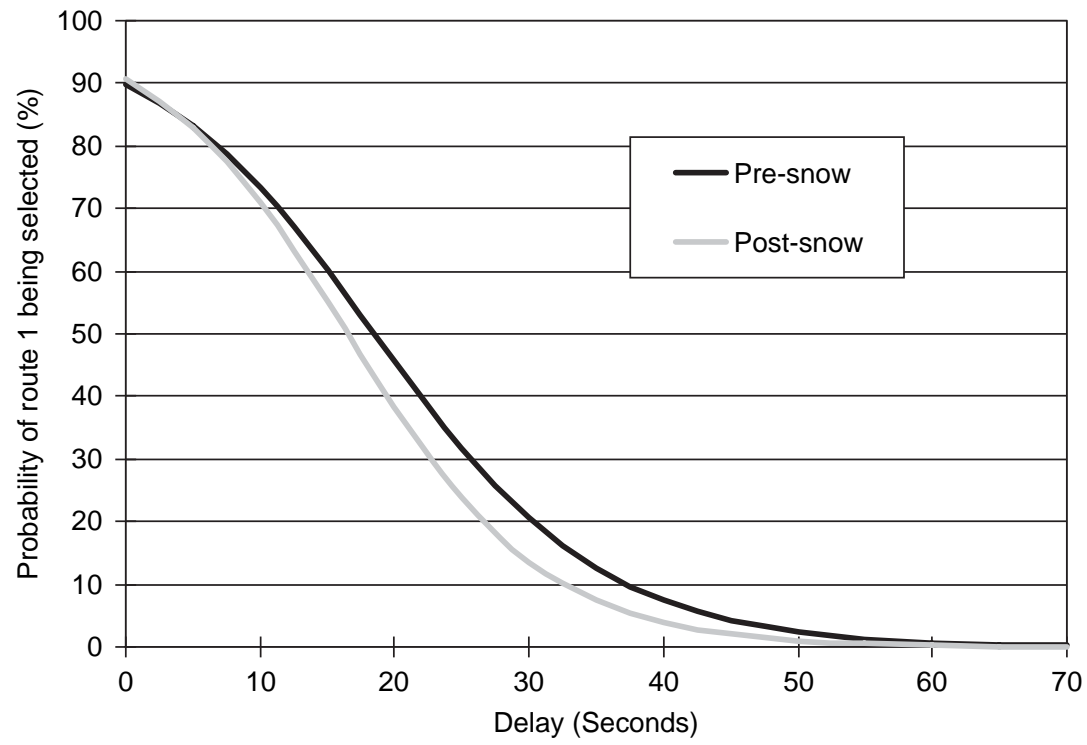

FIGURE 5 Probability that Route 1 will be selected as function of road surface condition and signal delay.

parameter values are shown in Table 7. The absolute $t$-values of all parameters are $>1.96$, and all have a $5 \%$ level of significance. Overall, the model is highly significant and shows a good fit when the likelihood ratio of 0.254 falls within the interval of 0.2 and 0.4 .

Figure 8 was plotted by using the parameter values obtained for the model that shows the probability that a route would be selected as a function of pedestrian delay at signalized intersections and the road surface conditions in winter. Figure $8 a$ indicates that if the surface condition of Route 1 is free of snow, then the probability that Route 1 will be selected becomes very high, despite the considerable delay at the signal. Furthermore, Figure $8 b$ shows that if the walkway surface of Route 1 is icy, then the probability that Route 1 will be selected is less than $50 \%$, even if the signal is green.

\section{DISCUSSION OF RESULTS AND CONCLUSIONS}

Two experimental methods were carried out to examine the effect of winter road surface conditions and signal delays on the walking behavior of pedestrians. In the field survey, the movements of pedestrians were observed by using video cameras mounted at a corner of each intersection for the selected sites. The resulting video records were analyzed by tracking the movements of each pedestrian. According to the field survey, when the signal was green the probability that a pedestrian would cross a crosswalk became extremely high, regardless

\section{TABLE 5 Three Surface Condition Levels}

\begin{tabular}{|c|c|c|}
\hline Service Level & Condition & Description \\
\hline Low & Extremely slippery & Icy \\
\hline Medium & Moderately slippery & $\begin{array}{l}\text { Approximately half of the road } \\
\text { section has road heating }\end{array}$ \\
\hline High & Not slippery & $\begin{array}{l}\text { Entire road section has } \\
\text { road heating }\end{array}$ \\
\hline
\end{tabular}

of the surface conditions of the walkways. However, when the signal was red and the walkway surface was icy, the probability that a pedestrian would cross a crosswalk decreased considerably. This indicates that when the wait becomes long, the probability that a pedestrian will cross a crosswalk becomes low during the snowy season.

The results of the questionnaire survey indicate that even if the surface condition on part of the route is good, it has a great influence on route choice behavior. Furthermore, the results show that if the surface condition of a route is slippery, then the probability that that route will be selected becomes less than $50 \%$, even when the signal is green. This is because pedestrians face difficulties in walking on slippery

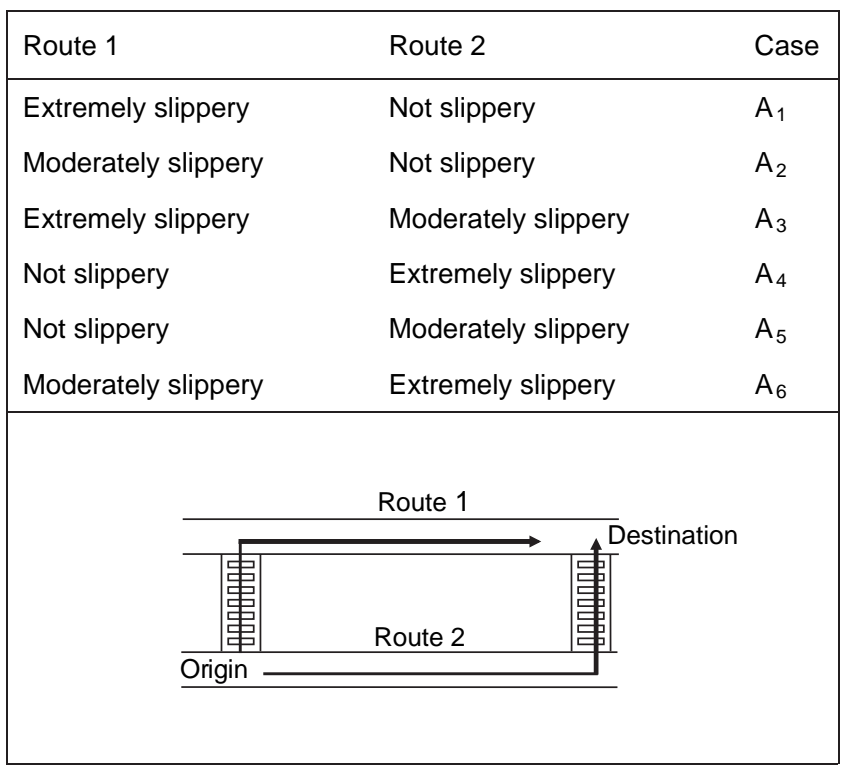

FIGURE 6 Three levels and six combinations of road surface conditions. 
Imagine you are at the origin and want to reach the destination shown in this figure.

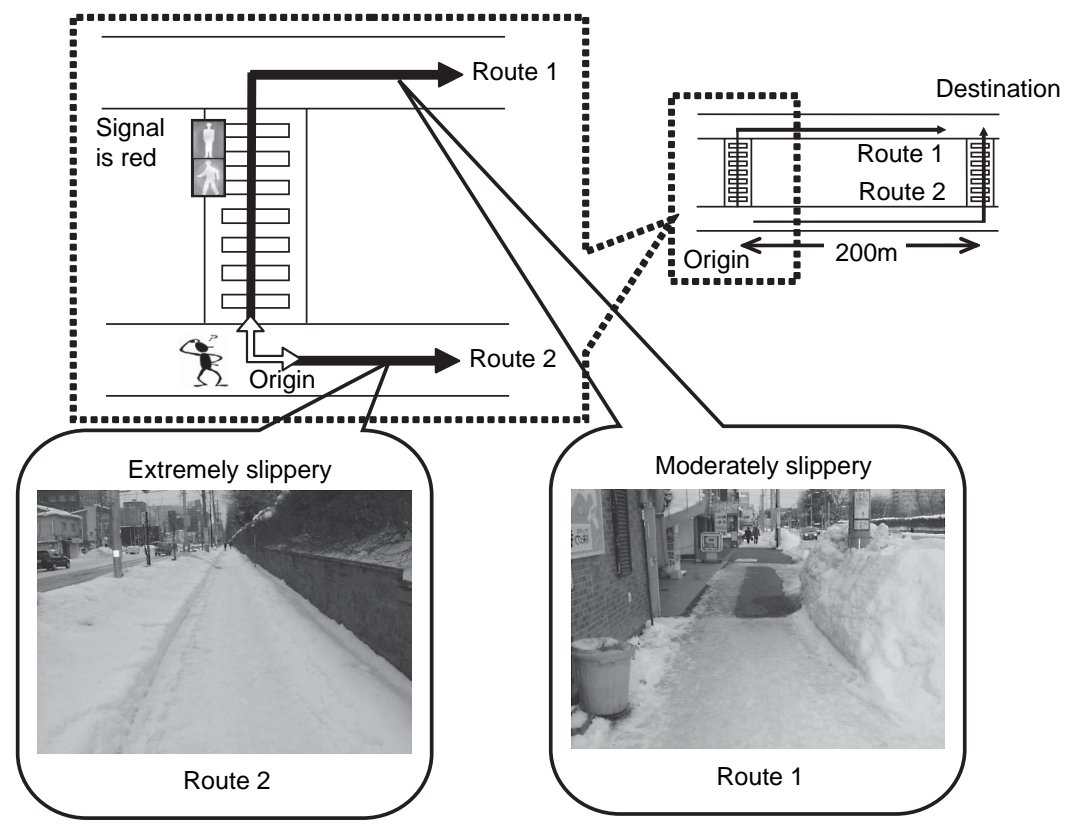

The signal is red. However, the signal will change to green in 15 seconds. Which route would you choose?

Route 1 (You'll wait for the green signal before crossing at the crosswalk)

Route 2 (You won't wait at the signal. Instead you'll immediately walk along the "extremely slippery" sidewalk)

FIGURE 7 Sample questionnaire used for the survey.

surfaces and prefer routes where even a part is kept bare by road heating. The overall results of the questionnaire survey indicate that walking behavior is greatly affected by the iciness of walkways.

On the basis of data from the field survey and the questionnaire survey, logit models were developed to express the route choice behavior of pedestrians quantitatively. These models can be used to evaluate the effects of winter road surface conditions and signal delays on pedestrian route choice behavior. Evaluation of the effect of winter road surface conditions on pedestrian route choice behavior can help road managers decide where to provide snow removal or how to improve slippery walkways. The results also suggest that transportation planners should consider the high degree of significance of pedestrian delay at signalized intersections when they design street networks.

TABLE 6 Personal Characteristics of Respondents

\begin{tabular}{llcc}
\hline Characteristic & Categories & $\begin{array}{l}\text { Number of } \\
\text { Participants }\end{array}$ & Percentage \\
\hline Gender & Male & 48 & 35 \\
& Female & 89 & 65 \\
Age & $<20$ years & 8 & 6 \\
& 20-29 years & 62 & 45 \\
& 30-39 years & 32 & 23 \\
& 40-49 years & 12 & 9 \\
& 50-59 years & 15 & 11 \\
& $>59$ years & 8 & 6 \\
\hline
\end{tabular}

In the field investigation, the results prove that signals have a great influence on the route choice behavior of pedestrians. However, the influence of a slippery surface on pedestrian route choice behavior was observed to be low. Major changes in route choice behavior were not recognized for routes whose road surface conditions differed. The correct selection of experimental sites is an important issue in the

TABLE 7 Results of Pedestrian Route Choice Model Obtained from Questionnaire Survey

\begin{tabular}{lcr}
\hline Parameter & Parameter Value & $t$-Value \\
\hline$\alpha$ & 1.702 & 11.320 \\
$\beta$ & -0.061 & -16.964 \\
$\gamma_{1}$ & -2.970 & -11.490 \\
$\gamma_{2}$ & -1.824 & -7.920 \\
$\gamma_{3}$ & -2.295 & -9.728 \\
$\gamma_{4}$ & 2.146 & 9.168 \\
$\gamma_{5}$ & 0.904 & 4.247 \\
$\gamma_{6}$ & 1.584 & 7.079 \\
Number of observations & $=1584$ & \\
Log likelihood function & $=-812.892$ & \\
Restricted log likelihood & $=-1089.019$ & \\
Chi-squared & $=552.2549$ & \\
Degrees of freedom & $=7$ & \\
Predicted outcome & $=74 \%$ & \\
Likelihood ratio & $=0.254$ & \\
\hline
\end{tabular}




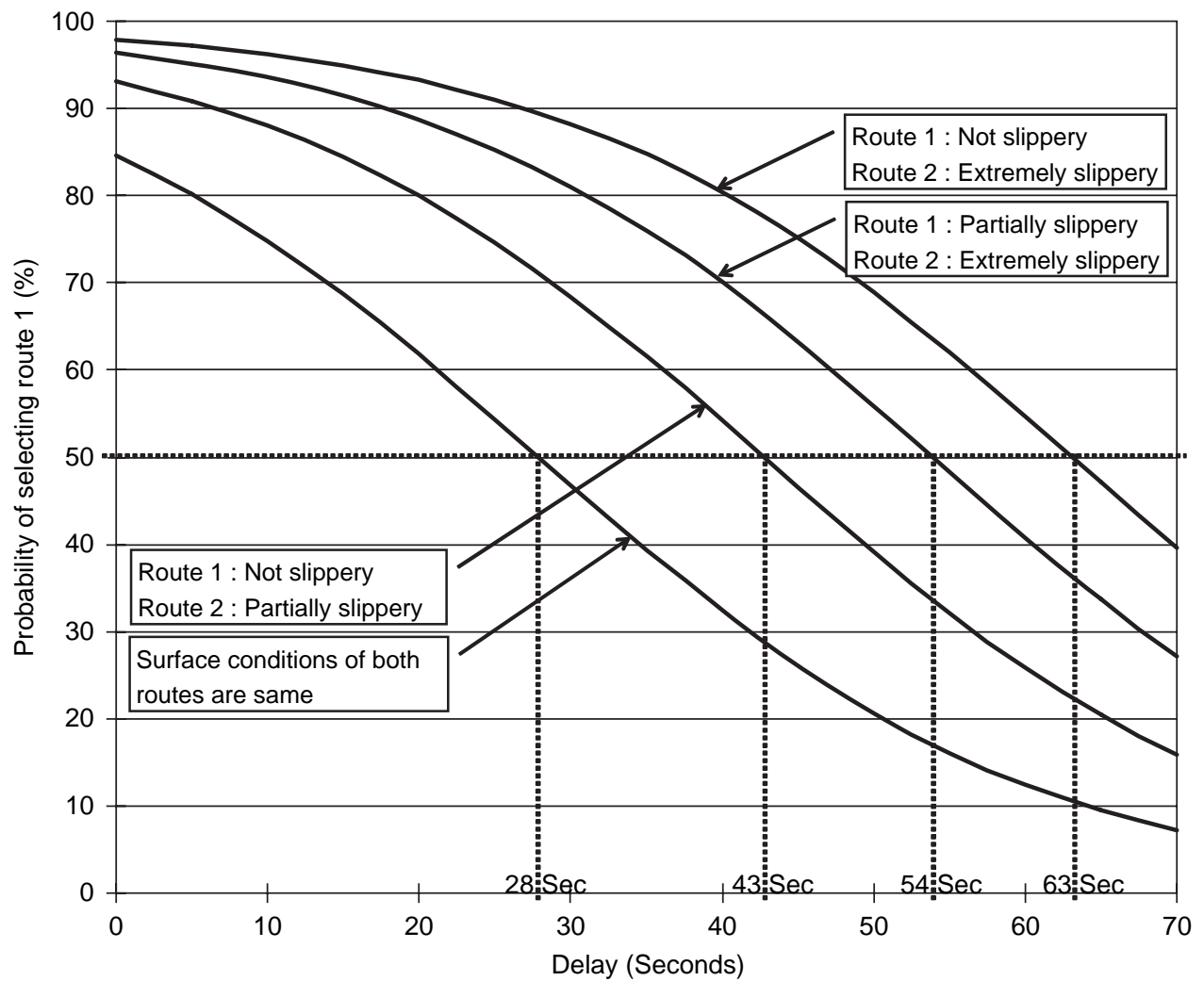

(a)

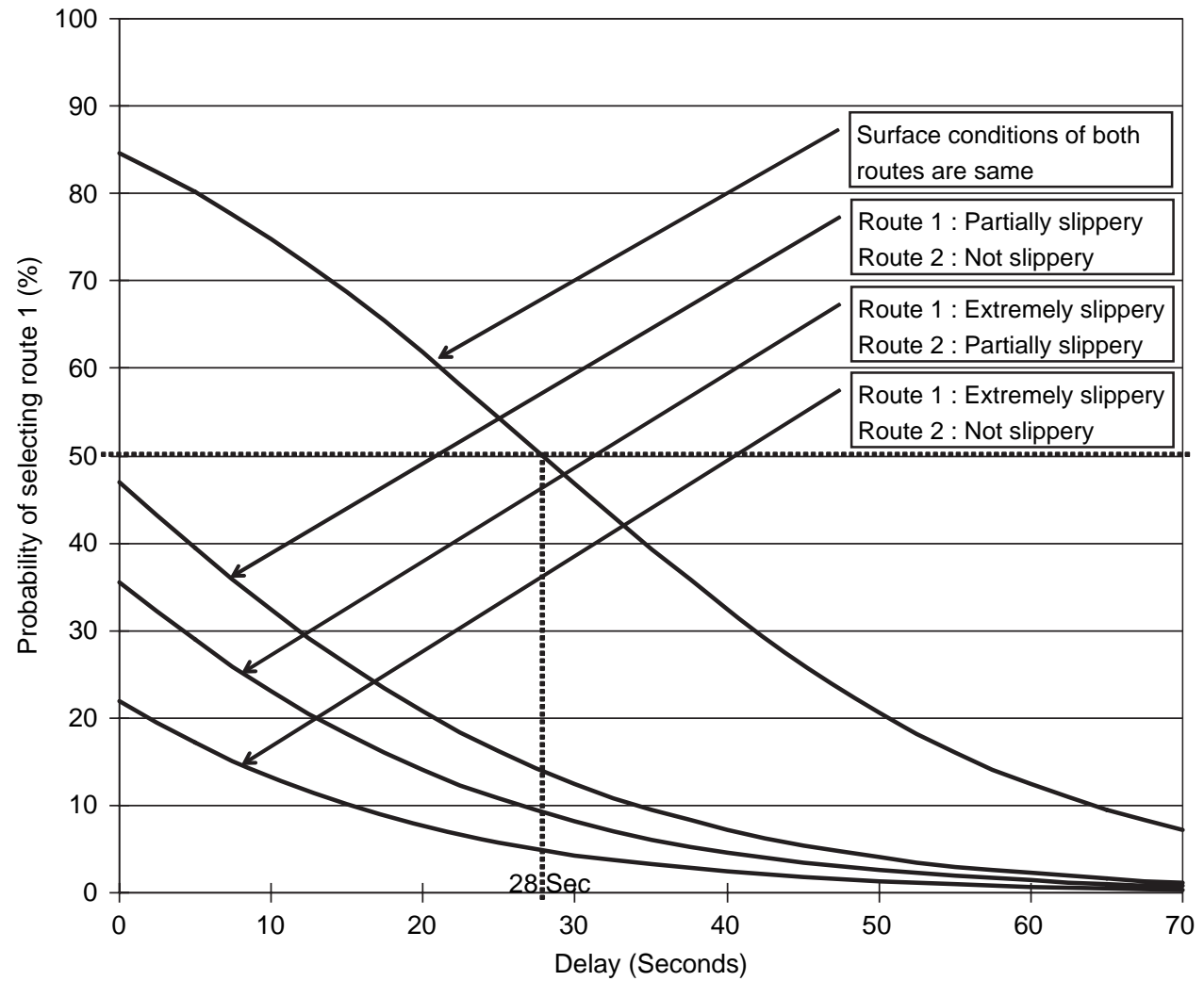

(b)

FIGURE 8 Probability that Route 1 will be selected as function of surface conditions and signal delay: (a) surface condition of Route 1 , better than that of Route 2 , and $(b)$ surface condition of Route 2, better than that of Route 1. 
field survey. In reality, selection of a proper site is not an easy task because different routes need to appear in different surface conditions for the purpose of this experiment. Although special devices have been developed to measure the degree of slipperiness on winter roads, they are not suitable for walkways. Because no equipment was available to measure slipperiness, the surface conditions of the routes were not evaluated. The routes selected may not have had the slipperiness required for the field investigation. The authors believe that selection of an appropriate site could improve the results of the field survey.

In the questionnaire survey, the results indicate that the influence of surface condition is greater than that of delay. The effect of delay may not be completely understood from the paper-based questionnaires. To overcome this problem, questionnaire surveys could be done by using video clips, so that the respondents would better realize the effect of the delay. Further investigations are necessary to examine the reasons for the differences between the results of the field investigation and the questionnaire investigation. This study was limited to one experimental site because of limited time and funding. Future research is planned for further analysis of field data that have been collected from other experimental sites. Furthermore, the issue of pedestrian route choice behavior can be examined by different methodologies. One such methodology is asking pedestrians to map their trips on a road network. By using this approach, frequent users of the study site can be identified. An analysis of only habitual users who are familiar with the sites with the exclusion of occasional users who are unfamiliar with the location promises to give better answers regarding the differences between what was observed and what pedestrians reported.

\section{REFERENCES}

1. Shintani, Y., F. Hara, K. Hari, and M. Yuri. Walking Experiment Under Icy Conditions. Presented at 81st Annual Meeting of the Transportation Research Board, Washington, D.C., 2002.

2. Highway Capacity Manual. TRB, National Research Council, Washington, D.C., 2000.

3. Daamen, W., and S. P. Hoogendoorn. Experimental Research on Pedestrian Walking Behavior. In Transportation Research Record: Journal of the Transportation Research Board, No. 1828, Transportation Research Board of the National Academies, Washington, D.C., 2003, pp. 20-30.

4. Eash, R. Destination and Mode Choice Models for Nonmotorized Travel. In Transportation Research Record: Journal of the Transportation Research Board, No. 1674, TRB, National Research Council, Washington, D.C., 1999, pp. 1-8.

5. Stinson, M. A., and C. R. Bhat. Commuter Bicyclist Route Choice: Analysis Using a Stated Preference Survey. In Transportation Research Record: Journal of the Transportation Research Board, No. 1828, Transportation Research Board of the National Academies, Washington, D.C., 2003, pp. 107-115.

6. Tsukaguchi, H., U. Vandebona, and K. Matsuda. Modelling of Pedestrian Route Choice Behaviour for Development of Information Systems Architecture. Proc., 9th World Conference on Transportation Research, Seoul, Korea, 2001.

7. LIMDEP User's Manual, Version 7.0. Economic Software Inc., New York, 1995.

The Pedestrians Committee sponsored publication of this paper. 